\title{
Timing of Hepatitis C Virus Treatment in Liver Transplant Candidates in the Era of Direct-acting Antiviral Agents
}

\author{
George Cholankeril ${ }^{1}$, Mairin Joseph-Talreja ${ }^{1}$, Brandon J. Perumpail ${ }^{2}$, Andy Liu ${ }^{3}$, Eric R. Yoo ${ }^{4}$, \\ Aijaz Ahmed*1 and Aparna Goel ${ }^{1}$

\begin{abstract}
${ }^{1}$ Division of Gastroenterology and Hepatology, Stanford University School of Medicine, Stanford, CA, USA; ${ }^{2}$ Department of San Francisco, CA, USA; ${ }^{4}$ Department of Medicine, Santa Clara Valley Medical Center, San Jose, CA, USA
\end{abstract} \\ Medicine, Drexel University College of Medicine, Philadelphia, PA, USA; ${ }^{3}$ Department of Medicine, California Pacific Medical Center,
}

\begin{abstract}
Chronic hepatitis $\mathrm{C}$ virus (HCV) infection remains the leading indication for liver transplantation (LT) in the United States. While most patients with chronic HCV infection remain asymptomatic, up to one-third develop progressive liver disease resulting in cirrhosis. LT is often the only curative treatment once significant hepatic decompensation develops. However, antiviral therapy for HCV infection has advanced markedly in the past 5 years with the discovery and approval of direct-acting antiviral agents. These new regimens are well tolerated, of short duration and highly effective, unlike the traditional treatment with pegylated-interferon and ribavirin. As achieving sustained virological response becomes increasingly attainable for a majority of HCV-infected patients, concerns have been raised regarding the optimal timing of treatment for HCV infection in the setting of end-stage liver disease and during the peri-transplant period. On one hand, $\mathrm{HCV}$ treatment may improve hepatic function and negate the need for LT in some, which is crucial given the scarcity of donor organs and mortality on the waiting list in certain regions. On the other hand, HCV treatment may result in lowering the priority for LT without improving quality of life, thereby delaying potentially curative LT surgery. This review evaluates the evidence supporting the use of direct-acting antiviral agents in the period before and following LT.

Citation of this article: Cholankeril G, Joseph-Talreja $M$, Perumpail BJ, Liu A, Yoo ER, Ahmed A, et al. Timing of hepatitis $C$ virus treatment in liver transplant candidates in the era of direct-acting antiviral agents. J Clin Transl Hepatol 2017;5 (4):363-367. doi: $10.14218 /$ JCTH.2017.00007.
\end{abstract}

\section{Introduction}

Chronic hepatitis C virus (HCV) infection remains one of the most common causes of liver disease in the United States.

Keywords: Hepatitis C virus; Direct-acting antiviral therapy; Liver transplantation. Abbreviations: CI, confidence interval; CTP, Child-Turcotte-Pugh; DAA, directacting antiviral; $\mathrm{FCH}$, fibrosing cholestatic hepatitis; $\mathrm{HCC}$, hepatocellular carcinoma; $\mathrm{HCV}$, hepatitis C virus; HR, hazard ratio; LT, liver transplantation; MELD, model for end-stage liver disease; SVR, sustained virological response.

Received: 19 January 2017; Revised: 30 July 2017; Accepted: 18 August 2017

*Correspondence to: Aijaz Ahmed, Division of Gastroenterology and Hepatology, Stanford University School of Medicine, 750 Welch Road, Suite \#210, Stanford, CA 94304, USA. Tel: +1-650-498-6091, Fax: +1-650-498-5692, E-mail: aijazahmed@stanford.edu
It is estimated that $1.0-1.5 \%$ of the United States' population, or 2.7 to 3.5 million persons, have chronic $\mathrm{HCV}$ infection and that more than 15,000 persons will die of HCV-related complications each year. ${ }^{1-3}$ End-stage liver disease due to HCV is currently the leading indication for liver transplantation (LT) in the US, accounting for over $30 \%$ of all transplants annually. ${ }^{4,5}$ However, treatment for chronic HCV infection has revolutionized in the past 5 years with the approval of second-generation direct-acting antiviral (DAA) agents.

These newer DAA-based regimens are highly effective, resulting in sustained virological response (SVR) in greater than $90 \%$ of patients. Data continue to demonstrate that SVR significantly reduces the risk of progressive liver disease, hepatic decompensation, hepatocellular carcinoma (HCC), liver-related mortality and all-cause mortality. ${ }^{6}$ However, the timing of treatment in HCV-infected patients awaiting LT remains controversial. The treatment of HCV followed by SVR in patients with cirrhosis may improve the model for end-stage liver disease (MELD) score, thereby lowering the likelihood of LT, without improving the poor quality of life associated with complications of end-stage liver disease; a situation termed 'MELD purgatory'. 7,8

This reviews aimed to aggregate and evaluate current data on the treatment of chronic HCV infection in the peri-transplant period and determine the validity of 'MELD purgatory'.

\section{Natural history of HCV infection}

Acute hepatitis develops in $20 \%$ of patients within 2 weeks of exposure to HCV. Symptoms during acute infection are often unnoticed, but some may experience jaundice, malaise, nausea and anorexia. Approximately $55-85 \%$ of patients are unable to spontaneously clear the virus and will develop chronic infection. Chronic HCV infection is a slowly progressive disease that leads to the development of cirrhosis in $10-40 \%$ of patients over $20-30$ years. ${ }^{9}$ The progression can be accelerated in specific populations, including the elderly, patients co-infected with human immunodeficiency virus ${ }^{10}$ and LT recipients. ${ }^{11}$

The vast majority of patients with chronic HCV infection are asymptomatic, although fatigue is a common complaint. Once cirrhosis has developed, there is a $1-5 \%$ annual risk of HCC and 3-6\% annual risk of hepatic decompensation with several host and viral factors influencing these rates. ${ }^{12}$ Chronic HCV infection is currently the leading cause of HCC among patients with cirrhosis, accounting for $55 \%$ of 
all HCC. ${ }^{13}$ In patients who develop hepatic decompensation, the risk of death within 1 year is approximately $15-20 \%$, and LT generally remains the only life-saving option. ${ }^{14}$

\section{HCV infection in liver transplant recipients}

LT serves as a curative management option for HCV-infected patients with severe hepatic decompensation with or without HCC. However, in chronically infected HCV-seropositive patients at the time of $L T$, recurrence of HCV infection in the graft is universal, with up to one-third of patients progressing from graft dysfunction to cirrhosis within 5 years of LT. ${ }^{15} \mathrm{Few}$ published cases describe spontaneous clearance of HCV infection following LT without a clearly defined mechanism. ${ }^{16}$ Nonetheless, such cases are rare. In a study evaluating 149 patients with recurrent post-transplant HCV infection, $12 \%$ experienced no evidence of chronic hepatitis on liver biopsy while $70 \%$ developed mild chronic hepatitis within 6 months. ${ }^{17}$

Prior to the approval and introduction of DAA agents, LT for HCV-positive patients was associated with lower outcomes, with increased rate of death (hazard ratio [HR]: $1.23,95 \%$ confidence interval [CI]: 1.12-1.35) and allograft failure (HR: $1.30,95 \% \mathrm{CI}: 1.21-1.39$ ) compared to LT for other indications. ${ }^{18}$ The inferior graft and survival rates were largely due to accelerated graft fibrosis from recurrent $\mathrm{HCV}$ infection along with ineffective and intolerable interferon-based therapies. In the era of DAA-based therapy, it is expected that outcomes for HCV-positive LT recipients will be similar, if not better than LT recipients for other indications. ${ }^{19,20}$

\section{Treatment of HCV prior to liver transplantation}

Achieving SVR after HCV treatment has repeatedly demonstrated lower rates of cirrhosis, hepatic decompensation, HCC, liver-related mortality and all-cause mortality. ${ }^{6}$ Prior to DAA agents, pegylated-interferon and ribavirin were the cornerstone of HCV treatment, but their use was limited due to lower clinical efficacy, poor tolerance due to adverse effects and inability to treat patients with hepatic decompensation. ${ }^{21}$ Treatment of chronic HCV infection with DAA agents has significantly improved outcomes in HCV-related liver disease due to high SVR rates, improved adherence and relatively liberal use in patients with decompensated cirrhosis. ${ }^{10}$ These qualities naturally fuel a desire to treat all patients with chronic HCV infection; however, the timing of treatment is an important factor to consider.

In 2015, the landmark SOLAR-1 trial reported encouraging results in patients treated with sofosbuvir, ledipasvir and ribavirin for 12-24 weeks, with an overall SVR-12 rate of 86$89 \%$ in a non-transplant cohort who are decompensated (Child-Turcotte-Pugh class B [CTP-B] and Child-Turcotte-Pugh class $C$ [CTP-C]). ${ }^{19}$ In post-transplant patients without cirrhosis or with compensated cirrhosis (Child-Turcotte-Pugh class A [CTP-A]), 96-98\% achieved SVR compared to $85-88 \%$ in patients with moderate hepatic impairment (Child-Turcotte-Pugh class B [CTP-B]) and 60-75\% $(n=9)$ in patients with severe hepatic impairment (Child-TurcottePugh class C [CTP-C]) with 12-24 weeks of sofosbuvir/ledipasvir plus ribavirin. Seven patients underwent re-transplantation, with four receiving the LT prior to completing HCV treatment; SVR was noted in six of these patients during the posttransplant phase. ${ }^{18}$ This suggests that HCV treatment in the pre-transplant phase with DAA agents can successfully prevent recurrent HCV infection in LT recipients.

Second generation DAA agents are also more effective than prior therapies in special sub-populations of HCVinfected patients previously termed difficult-to-treat. SVR rates with DAA agents in the geriatric population are comparable to younger populations. ${ }^{22}$ ASTRAL-1, an international multicenter trial, noted the high efficacy of sofosbuvir and velpatasvir treatment in patients that failed prior HCV treatment and African Americans. ${ }^{23}$ Companion trials, ASTRAL-2 and ASTRAL-3, subsequently showed comparable SVR results in patients with HCV genotypes 2 and 3, which previously had lower SVR rates. ${ }^{24}$ These studies suggest that DAA agents can improve outcomes for a broad range of patients, including populations who were less likely to achieve SVR with interferon-based therapies.

Additionally, DAA agents have demonstrated efficacy and tolerability in patients with moderate to severe hepatic decompensation. A recent pooled analysis from all major clinical trials with DAA-based regimens used in CTP-B/C patients for all HCV genotypes found an overall SVR rate of $83.5 \%$. Furthermore, treatment with DAA agents led to stabilization or improvement in hepatic function in up to $60 \%$ of decompensated patients, while $17 \%$ had no change and $23 \%$ had a worsening in MELD score. ${ }^{25}$ An analysis of safety data from the SOLAR studies demonstrated that the combination of sofosbuvir and ledipasvir with ribavirin in decompensated patients was safe and well-tolerated, with expectant rates of severe adverse events (28-30\%) and death $(5 \%) .{ }^{26}$ Importantly, enrollment of patients with MELD score $>20$ and CTP-C disease in these trials was often limited, so these estimates may not be applicable to patients with higher MELD scores or severe liver decompensation.

Table 1. Advantages and disadvantages of HCV treatment in liver transplant candidates before liver transplantation

\begin{tabular}{ll}
\hline Advantages & Disadvantages \\
\hline $\begin{array}{l}\text { Liver function and MELD } \\
\text { score may improve }\end{array}$ & $\begin{array}{l}\text { MELD may improve but with } \\
\text { ongoing poor health (i.e., } \\
\text { 'MELD purgatory') }\end{array}$ \\
$\begin{array}{l}\text { Liver transplant may no } \\
\text { longer be necessary }\end{array}$ & $\begin{array}{l}\text { Possibly eliminates the } \\
\text { option of a curative } \\
\text { treatment for liver disease }\end{array}$ \\
$\begin{array}{l}\text { Societal benefit given } \\
\text { scarcity of organs and }\end{array}$ & $\begin{array}{l}\text { May limit access to hepatitis } \\
\text { limited donor pool }\end{array}$ \\
$\begin{array}{l}\text { thereby prolonging time on } \\
\text { liver transplant waitlist and } \\
\text { risk of death or dropout }\end{array}$ \\
$\begin{array}{l}\text { Prevent post-transplant } \\
\text { recurrence of hepatitis C } \\
\text { virus infection }\end{array}$ & $\begin{array}{l}\text { If HCV treatment fails, risk } \\
\text { of resistance to NS5A } \\
\text { inhibitors and compromised } \\
\text { sustained virological }\end{array}$ \\
& $\begin{array}{l}\text { response rates when re- } \\
\text { treating post-liver } \\
\text { transplantation }\end{array}$ \\
\hline $\begin{array}{l}\text { Cost effective strategy if } \\
\text { liver transplantation can } \\
\text { be obviated }\end{array}$ & \\
\hline
\end{tabular}

Abbreviation: MELD, model for end-stage liver disease. 
While HCV treatment of all patients prior to LT is desirable, it may not be beneficial for patients if transplantation cannot be obviated. ${ }^{27}$ This may be true for LT candidates with HCC or severely decompensated liver disease when LT surgery is the only curative option. ${ }^{28} \mathrm{HCV}$ treatment prior to LT in this cohort may reduce the available donor pool, as HCV-positive donors may no longer be considered an option. Such allografts are increasingly available in the current opioid epidemic, often from first-time and naive opiate users who are otherwise healthy. The proportion of HCV-positive donors in the local regional donor pool is an important factor to consider prior to treatment. ${ }^{29}$ In a single-center retrospective review of all deceased-donor transplants, Ofosu et al. ${ }^{30}$ observed that $40 \%$ of their HCV-seropositive recipients ultimately received transplants from HCV-positive donors. This number is likely to vary by region but should be considered when pursuing HCV treatment in a LT candidate. Treatment of such patients in a region with a high prevalence of $\mathrm{HCV}$-positive donors may result in extending LT waiting time, thereby increasing the risk of waitlist dropout while awaiting a suitable donor. In the future, policies may change with universal acceptance and uniform distribution of HCV-positive donors for patients with and without HCV infection awaiting LT.

Patients treated for HCV prior to LT may still accept an HCV-positive donor but would need to be re-treated post-transplantation, incurring additional healthcare costs. A recent analysis of the cost effectiveness in treating patients before or after LT indicated that treatment is likely to be cost effective in patients whose risk of LT can be successfully modified with treatment. Treatment in such patients would improve MELD scores and risk of hepatic complications, which subsequently reduces the risk of repeated hospitalizations, death and possibly LT. In patients whose risk of LT cannot be modified, such as for patients with HCC or severe liver dysfunction, HCV treatment prior to LT would not be cost effective. ${ }^{31}$ Advantages and disadvantages of this treatment strategy are summarized in Table 1.

\section{Treatment of HCV following liver transplantation}

Achievement of SVR in the post-LT setting is associated with significantly reduced morbidity and mortality in LT recipients. ${ }^{32}$ The standard of care for post-transplant HCV treatment prior to DAA agents was pegylated-interferon and ribavirin, which was suboptimal at best. A systematic review of 19 studies evaluating 611 post-transplant HCV-infected patients treated with interferon-based therapy demonstrated SVR rate of $30.2 \%(8-50 \%)$. This was due to the poor adverse effects profile often leading to dose reduction and discontinuation of treatment $(73 \%$ and $27.6 \%$, respectively). ${ }^{33}$ However, post-transplant HCV treatment with DAA agents has shown improved SVR rates due to improved efficacy and tolerability.

A recent retrospective study noted that treatment with a combination of sofosbuvir and simeprevir achieved SVR in $88 \%$ of LT recipients. In the more difficult-to-treat cohort with advanced fibrosis (defined as stage 3 or 4 on liver biopsy), only $64 \%$ achieved SVR. ${ }^{34,35}$ In another study from Canada, 120 LT recipients with recurrent HCV infection were treated with sofosbuvir-based regimens and $85 \%$ achieved SVR; of the 53 patients with advanced fibrosis, $81 \%$ achieved SVR. ${ }^{36}$ Treatment with sofosbuvir is also highly effective in the post-transplant period in patients with fibrosing cholestatic hepatitis $(\mathrm{FCH})$, a more aggressive form of HCV recurrence associated with worse outcomes. In a recent study evaluating five patients that developed $\mathrm{FCH}$, all were treated with sofosbuvir and simeprevir for 24 weeks and were noted to have undetectable levels of HCV RNA by the end of treatment. ${ }^{37}$

These recent studies demonstrating safety and efficacy of DAA agents in the post-transplant setting, especially in

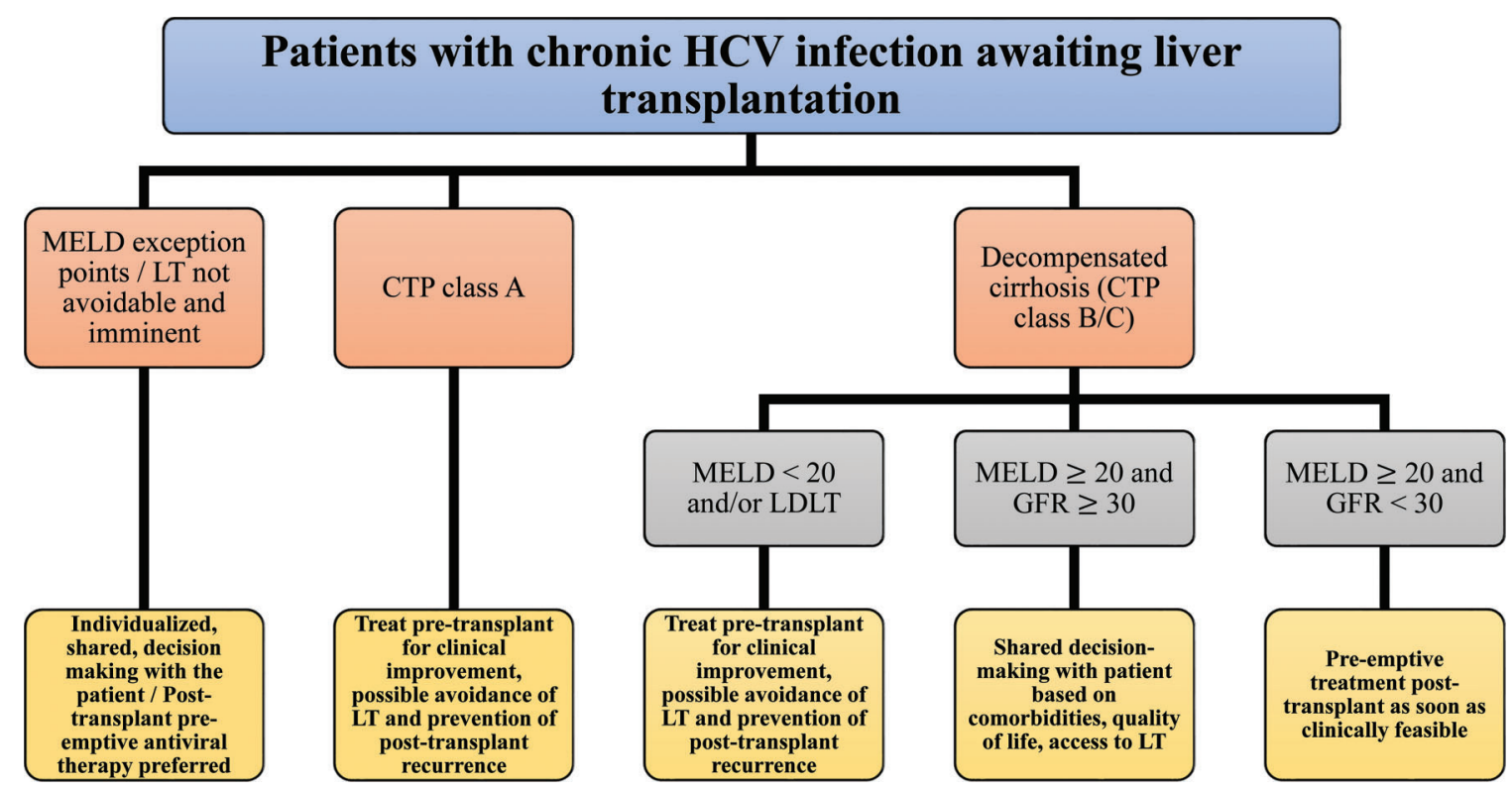

Fig. 1. Algorithm for treatment of HCV-infected liver transplant candidates.

Abbreviations: MELD, model for end-stage liver disease; LT, liver transplantation; CTP, Child-Turcotte-Pugh; LDLT, living donor liver transplantation; GFR, glomerular filtration rate. 
patients with advanced fibrosis and $\mathrm{FCH}$, are encouraging. Although larger prospective trials are required to establish specific therapy recommendations, timely pre-emptive treatment in patients unable to achieve SVR prior to LT appears to be a prudent approach and may reduce the burden of graft failure and re-transplantation.

\section{MELD purgatory - fact or fiction}

Despite the efficacy of DAA agents and significant clinical benefits of SVR, there remain concerns that HCV treatment for some patients on the LT waiting list may be ill-served in the current organ allocation system due to the possibility of 'MELD purgatory'. This refers to a limbo situation in which the LT candidate's MELD score may decrease but without an improvement in quality of life. In such patients there is a realistic risk of not receiving adequate priority on the LT waitlist, and perhaps HCV treatment following LT would be more appropriate.

Ideally, a prediction model could help identify which patients with hepatic decompensation are likely to experience clinical and biochemical improvement in hepatic function following HCV treatment and can be safely removed from the LT waitlist. Recent European studies evaluated the change in waitlist status of patients treated for HCV and found that patients listed with MELD $\geq 18$ were less likely to attain significant biochemical or clinical improvement and remained active on the waitlist following treatment. These studies concluded that if transplantation is imminent, post-transplant treatment may be a better option for such patients. ${ }^{38,39}$

In the United States, algorithms for HCV treatment in waitlisted patients have been proposed in an effort to avoid 'MELD purgatory' and optimize survival. ${ }^{40}$ Authors recommend pre-transplant HCV treatment in patients with hepatic decompensation and MELD $<20$, in patients scheduled for living donor LT, and in patients with MELD scores 20-27 based on regional trends in LT. Post-transplant treatment is recommended for patients with MELD $>27$ and/or significant renal impairment (with glomerular filtration rate $<30) .{ }^{40}$ We propose a modified algorithm, as summarized in Fig. 1, in an effort to avoid 'MELD purgatory'. For the time-being, it is clear that patients with lower MELD scores and mild hepatic impairment benefit from HCV treatment pre-transplant and carefully selected patients with moderate hepatic decompensation may benefit as well, with the exception of those anticipating imminent LT.

\section{Conclusions}

The introduction of DAA agents has dramatically altered the treatment landscape for the $\mathrm{HCV}$-infected patient population. DAA agents are better tolerated, safe and more effective in achieving SVR across the board, as compared to prior therapies. Given the benefits of SVR on liver function and mortality, the question is not if all patients should be treated for HCV, but rather when an individual patient should be treated, such that overall survival is maximized while maintaining access to LT if liver-related complications fail to improve despite a decline in MELD score. Unfortunately, the answers to these questions are not straightforward. Initial data suggest that patients with mild hepatic impairment and select patients with moderate impairment may improve to a point where LT is no longer required. Ultimately, robust predictors of improvement in hepatic function and quality of life are needed to identify patients for HCV treatment in the context of LT.

\section{Conflict of interest}

The authors have no conflict of interests related to this publication.

\section{Author contributions}

Drafted the initial and final manuscript (GC), supervised the project $(A A, A G)$, contributed to study concept and design, acquisition of data, analysis and interpretation of data, and critical revision of the manuscript (GC, MJT, BJP, AL, ERY, $A A, A G)$.

\section{References}

[1] Ryerson AB, Eheman CR, Altekruse SF, Ward JW, Jemal A, Sherman RL, et al. Annual Report to the Nation on the Status of Cancer, 1975-2012, featuring the increasing incidence of liver cancer. Cancer 2016;122:1312-1337. doi: 10.1002/cncr.29936.

[2] Denniston MM, Jiles RB, Drobeniuc J, Klevens RM, Ward JW, McQuillan GM, et al. Chronic hepatitis $C$ virus infection in the United States, National Health and Nutrition Examination Survey 2003 to 2010. Ann Intern Med 2014;160: 293-300. doi: 10.7326/M13-1133.

[3] Edlin BR, Eckhardt B], Shu MA, Holmberg SD, Swan T. Toward a more accurate estimate of the prevalence of hepatitis $C$ in the United States. Hepatology 2015;62:1353-1363. doi: 10.1002/hep.27978.

[4] Crespo G, Mariño Z, Navasa M, Forns X. Viral hepatitis in liver transplantation. Gastroenterology 2012;142:1373-1383.e1. doi: 10.1053/j.gastro. 2012.02.011.

[5] Moyer VA. U.S. Preventive Services Task Force. Screening for hepatitis C virus infection in adults: U.S. Preventive Services Task Force recommendation statement. Ann Intern Med 2013;159:349-357. doi: 10.7326/00034819-159-5-201309030-00672.

[6] van der Meer AJ, Veldt BJ, Feld JJ, Wedemeyer H, Dufour JF, Lammert F, et al. Association between sustained virological response and all-cause mortality among patients with chronic hepatitis $\mathrm{C}$ and advanced hepatic fibrosis. JAMA 2012;308:2584-2593. doi: 10.1001/jama.2012.144878.

[7] Carrion AF, Khaderi SA, Sussman NL. Model for end-stage liver disease limbo, model for end-stage liver disease purgatory, and the dilemma of treating hepatitis $C$ in patients awaiting liver transplantation. Liver Transpl 2016; 22:279-280. doi: 10.1002/It.24383.

[8] Bunchorntavakul C, Reddy KR. Treat chronic hepatitis C virus infection in decompensated cirrhosis - pre- or post-liver transplantation? the ironic conundrum in the era of effective and well-tolerated therapy. J Viral Hepat 2016;23:408-418. doi: 10.1111/jvh.12534.

[9] Lingala S, Ghany MG. Natural history of hepatitis C. Gastroenterol Clin North Am 2015;44:717-734. doi: 10.1016/j.gtc.2015.07.003.

[10] Osinusi A, Meissner EG, Lee Y], Bon D, Heytens L, Nelson A, et al. Sofosbuvir and ribavirin for hepatitis $C$ genotype 1 in patients with unfavorable treatment characteristics: a randomized clinical trial. JAMA 2013;310:804-811. doi: 10.1001/jama.2013.109309.

[11] Davis GL, Alter MJ, El-Serag $\mathrm{H}$, Poynard T, Jennings LW. Aging of hepatitis C virus (HCV)-infected persons in the United States: a multiple cohort model of HCV prevalence and disease progression. Gastroenterology 2010;138: 513-521.e6. doi: 10.1053/j.gastro.2009.09.067.

[12] Wray CM, Davis AM. Screening for hepatitis C. JAMA 2015;313:1855-1856. doi: 10.1001/jama.2015.2833.

[13] Snowberger N, Chinnakotla S, Lepe RM, Peattie J, Goldstein R, Klintmalm GB, et al. Alpha fetoprotein, ultrasound, computerized tomography and magnetic resonance imaging for detection of hepatocellular carcinoma in patients with advanced cirrhosis. Aliment Pharmacol Ther 2007;26:1187-1194. doi: 10. $1111 /$ j.1365-2036.2007.03498.x.

[14] Bunchorntavakul C, Reddy KR. Management of hepatitis C before and after liver transplantation in the era of rapidly evolving therapeutic advances. J Clin Transl Hepatol 2014;2:124-133. doi: 10.14218/JCTH.2014.00002.

[15] Ferrarese A, Zanetto A, Gambato M, Bortoluzzi I, Nadal E, Germani G, et al. Liver transplantation for viral hepatitis in 2015. World J Gastroenterol 2016; 22:1570-1581. doi: 10.3748/wjg.v22.i4.1570.

[16] Kogiso T, Hashimoto E, Ikarashi Y, Kodama K, Taniai M, Torii N, et al. Spontaneous clearance of $\mathrm{HCV}$ accompanying hepatitis after liver transplantation. Clin J Gastroenterol 2015;8:323-329. doi: 10.1007/s12328-015-0602-y. 
[17] Gane EJ, Portmann BC, Naoumov NV, Smith HM, Underhill JA, Donaldson PT, et al. Long-term outcome of hepatitis $\mathrm{C}$ infection after liver transplantation. N Engl J Med 1996;334:815-820. doi: 10.1056/NEJM199603283341302.

[18] Forman LM, Lewis JD, Berlin JA, Feldman HI, Lucey MR. The association between hepatitis $C$ infection and survival after orthotopic liver transplantation. Gastroenterology 2002;122:889-896. doi: 10.1053/gast.2002.32418.

[19] Charlton M, Everson GT, Flamm SL, Kumar P, Landis C, Brown RS Jr, et al. Ledipasvir and sofosbuvir plus ribavirin for treatment of HCV infection in patients with advanced liver disease. Gastroenterology 2015;149: 649-659. doi: 10.1053/j.gastro.2015.05.010.

[20] Curry MP, Forns X, Chung RT, Terrault NA, Brown R Jr, Fenkel JM, et al. Sofosbuvir and ribavirin prevent recurrence of HCV infection after liver transplantation: an open-label study. Gastroenterology 2015;148:100-107.e1. doi: 10.1053/j.gastro.2014.09.023.

[21] Everson GT, Terrault NA, Lok AS, Rodrigo del R, Brown RS Jr, Saab S, et al. A randomized controlled trial of pretransplant antiviral therapy to prevent recurrence of hepatitis $C$ after liver transplantation. Hepatology 2013;57: 1752-1762. doi: 10.1002/hep.25976.

[22] Saab S, Park SH, Mizokami M, Omata M, Mangia A, Eggleton E, et al. Safety and efficacy of ledipasvir/sofosbuvir for the treatment of genotype 1 hepatitis $C$ in subjects aged 65 years or older. Hepatology 2016;63:1112-1119. doi: $10.1002 /$ hep. 28425 .

[23] Feld J], Jacobson IM, Hézode C, Asselah T, Ruane PJ, Gruener N, et al. Sofosbuvir and velpatasvir for HCV genotype 1, 2, 4, 5, and 6 infection. $N$ Engl J Med 2015;373:2599-2607. doi: 10.1056/NEJMoa1512610.

[24] Foster GR, Afdhal N, Roberts SK, Bräu N, Gane EJ, Pianko S, et al. Sofosbuvir and velpatasvir for HCV genotype 2 and 3 infection. N Engl J Med 2015;373: 2608-2617. doi: 10.1056/NEJMoa1512612.

[25] Foster GR, Irving WL, Cheung MC, Walker AJ, Hudson BE, Verma S, et al. Impact of direct acting antiviral therapy in patients with chronic hepatitis $C$ and decompensated cirrhosis. J Hepatol 2016;64:1224-1231. doi: 10. 1016/j.jhep.2016.01.029.

[26] Samuel D, Manns M, Forns X, Flamm SL, Reddy KR, Denning J, et al. Ledipasvir/sofosbuvir with ribavirin is safe in $>600$ decompensated and post liver transplantation patients with HCV infection: An integrated safety analysis of the solar 1 and solar 2 trials. J Hepatol 2015;62:S620-S621. doi: 10 . 1016/S0168-8278(15)30977-6.

[27] Saab S, Jimenez M, Fong T, Wu C, El Kabany M, Tong MJ. Timing of antivira therapy in candidates for liver transplant for hepatitis $\mathrm{C}$ and hepatocellular carcinoma. Exp Clin Transplant 2016;14:66-71. doi: 10.6002/ect.2015. 0069.

[28] Burra P, Belli LS, Ginanni Corradini S, Volpes R, Marzioni M, Giannini E, et al. Common issues in the management of patients in the waiting list and after liver transplantation. Dig Liver Dis 2017;49:241-253. doi: 10.1016/j.dld. 2016.12.027.
[29] Goldberg DS, Blumberg E, McCauley $M$, Abt $P$, Levine $M$. Improving organ utilization to help overcome the tragedies of the opioid epidemic. Am J Transplant 2016;16:2836-2841. doi: 10.1111/ajt.13971.

[30] Ofosu A, Durand CM, Saberi B, Alqahtani S, Ucbilek E, Belden M, et al. Implications of treating hepatitis $C$ virus infection among patients awaiting cadaveric liver transplant: a single-center experience. Exp Clin Transplant 2015; 13:7-10. doi: 10.6002/ect.tdtd2015.L16.

[31] Tapper EB, Afdhal NH, Curry MP. Before or after transplantation? a review of the cost effectiveness of treating waitlisted patients with hepatitis C. Transplantation 2017;101:933-937. doi: 10.1097/TP.0000000000001611.

[32] Picciotto FP, Tritto G, Lanza AG, Addario L, De Luca M, Di Costanzo GG, et al. Sustained virological response to antiviral therapy reduces mortality in $\mathrm{HCV}$ reinfection after liver transplantation. J Hepatol 2007;46:459-465. doi: 10. 1016/j.jhep.2006.10.017.

[33] Berenguer M. Systematic review of the treatment of established recurrent hepatitis $C$ with pegylated interferon in combination with ribavirin. J Hepatol 2008;49:274-287. doi: 10.1016/j.jhep.2008.05.002.

[34] Crittenden NE, Buchanan LA, Pinkston CM, Cave B, Barve A, Marsano L, et al. Simeprevir and sofosbuvir with or without ribavirin to treat recurrent genotype 1 hepatitis $C$ virus infection after orthotopic liver transplantation. Liver Transpl 2016;22:635-643. doi: 10.1002/lt.24422.

[35] Jackson WE, Hanouneh M, Apfel T, Alkhouri N, John BV, Zervos X, et al. Sofosbuvir and simeprevir without ribavirin effectively treat hepatitis $C$ virus genotype 1 infection after liver transplantation in a two-center experience. Clin Transplant 2016;30:709-713. doi: 10.1111/ctr.12738.

[36] Faisal N, Bilodeau M, Aljudaibi B, Hirsch G, Yoshida EM, Hussaini T, et al. Sofosbuvir-based antiviral therapy is highly effective in recurrent hepatitis $C$ in liver transplant recipients: canadian multicenter "real-life" experience. Transplantation 2016;100:1059-1065. doi: 10.1097/TP.0000000000001126.

[37] Issa D, Eghtesad B, Zein NN, Yerian L, Cruise M, Alkhouri N, et al. Sofosbuvir and simeprevir for the treatment of recurrent hepatitis $\mathrm{C}$ with fibrosing cholestatic hepatitis after liver transplantation. Int J Organ Transplant Med $2016 ; 7: 38-45$

[38] Belli LS, Berenguer M, Cortesi PA, Strazzabosco M, Rockenschaub SR, Martini $S$, et al. Delisting of liver transplant candidates with chronic hepatitis C after viral eradication: A European study. J Hepatol 2016;65:524-531. doi: 10.1016/j.jhep.2016.05.010.

[39] Fernández Carrillo C, Lens S, Llop E, Pascasio JM, Crespo J, Arenas J, et al. Treatment of hepatitis $C$ virus infection in patients with cirrhosis and predictive value of model for end-stage liver disease: Analysis of data from the Hepa-C registry. Hepatology 2017;65:1810-1822. doi: 10.1002/hep. 29097.

[40] Verna EC. The dynamic landscape of liver transplant in the era of effective hepatitis C virus therapy. Hepatology 2017;65:763-766. doi: 10.1002/hep. 29054. 